E.L.U.A., 5, 1988-1989, pp. 49-66

\title{
MODALIDADES ACTANCIALES EN LOS SONETOS DE GUTIERRE DE CETINA
}

\author{
AMELIA FERNANDEZ RODRIGUEZ \\ (Universidad Autónoma de Madrid)
}

Es de sobra conocido el juicio crítico que le mereció a Herrera la obra de Gutierre de Cetina; "Y si acompañara la erudición y la destreza de la arte al ingenio y trabajo, y pusiera intención en la fuerza como en la suavidad y pureza ninguno le fuera aventajado" 1 . Media un abismo entre dos generaciones y dos formas de entender y vivir el ejercicio poético; aquella del poeta-soldado inmerso en los fragores de las distancias y la guerra así como entregado al leve discreteo galante de la Corte; y la de aquel otro poeta erudito para el que el ruido de la vida alcanza "numerosa" intensidad en el apartado silencio del estudio.

Tampoco fue exigente Cetina al escoger lecturas que sedimentaran en su propia voz. Al lado de los grandes poetas no reparó en elegir las más varias modulaciones de calidad disonante, o bien ajustarse al modo poético de otro autor plenamente medieval, Ausias March, con una fijeza y una frecuencia inusual ${ }^{2}$. Tal y como ya había afirmado $A$. $M$. Withers, "his verses present him to us as a care-free and impetuous young soldier who, subject only to the will of his sovereign and commander, lived as he pleased, loved as he pleased, and gathered materials for poetry where he pleased" 3 .

Esta misma anarquía se refleja en un universo lírico que no responde al "desarrollo

' Citamos por la edición de A. Gallego Morell, Garcilaso de la Vega y sus comentaristas, Madrid, (iredos, 1972 (2a edición revisada y adicionada); H-I.

${ }^{2}$ R. Lapesa, La poesía de Gutierre de Cetina en "Hommage a E. Martinenche", Paris, 1939, pp. 248-261; en comparación con (aarcilaso "Cetina es menos escrupuloso; coge ideas, motivos, imágenes, versos o estrofas enteras de la lírica que florecía en las cortes italianas, sin seleccionarla; tan pronto se inspira en Petarca, Bembo, Sannazaro, Ariosto o Tansillo como en Serafino Aquilano, Andrea Gesualdo y otros rimadores de segundo o tercer orden. Su memoria no se desprende de los hermosísimos pero medievales Cants d'amor. Con frecuencia se limita a traducir obras ajenas sin añadirles notas propias". (p. 249)

${ }^{3}$ A. M. Withers, The sources of the poetry of Gittierre de Cetina, Philadelphia, 1923; p. 42. 
gradual y armónico" 4 filtrado por entre el "dolorido sentir" garcilasiano sino que debe sus aciertos, y a la vez carencias, a la naturaleza de un hábil versificador que improvisa; como también a la tierna "piacevolezza" que aprendió de la lectura de las Rime diverse y de sus contactos directos con Italia s. Lo cierto es que la amplia producción de Cetina deja a la poesía petrarquista practicada en España un repertorio de fórmulas posibles en virtud del sentido arquitectónico que Cetina intuye para el soneto ${ }^{6}$. Así lo entendió Herrera cuando "anota"; "En Cetina, cuanto a los Sonetos particularmente, se conoce la hermosura y gracia de Italia; y en número, lengua, terneza y afectos ninguno le negará lugar con los primeros..."? .

El trabajo que presentamos parte de los parámetros de análisis establecidos por el profesor D. Antonio García Berrio en su teoría tipológico-textual del soneto clásico ${ }^{8}$. Prestaremos atención preferente a uno de los aspectos más importantes de la teoría; la organización de las modalidades actanciales en la obra de Gutierre de Cetina.

En el estadio actual de la teoría se contempla la concurrencia de tres funciones actanciales básicas mediante las que el poeta modula la expresión de su sentimiento. La función predominante es la sintomática, desviada en algunos textos hacia estructuras narrativas, pero también puede el poeta canalizar la expresión a través de un movimiento "apelativo" dirigido al "término", Dama, o a un confidente, humano o no, como "representar" en el texto sucesos ajenos en principio a su propia historia amorosá. De la siguiente manera establece el profesor García Berrio la incidencia constructiva de las tres funciones:

${ }^{4}$ R. Lapesa, art. cit.; "La lírica de (etina no se proyecta como desarrollo gradual y armónico, sino como fruto de un espíritu versátil y disperso..." (p. 249).

${ }^{5}$ Ver especialmente M. Bataillon, Gutieme de Cetina en Italia, en "Studia Hispanica in honorem R. Lapesa", Madrid, 1972, pp. 153-172. Una acertada síntesis de las diversas aportaciones críticas a la biografía de Cetina se halla en la primera parte de la monografía que B. Lópe\%. Bucno dedica al pocta; Cítierre de Cetina, poeta del Renacimiento español, Sevilla, Publicaciones de la Diputación provincial, 1978.

- R. Lapesa, art. cit.; "Cetina introduce en la pocsía española la claboración artística del sonclo, con arreglo a varios lipos que habían de tener fortuna." (p. 260). En el mismo sentido de pronuncia D. Alonso, Primer escatón de los manierismos del siglo XVI. Plurimembración y correlaciones de Ciarcilaso a Gutierre de Cetina, en "Asclepio", XVIII-XIX, 1966-1967, pp. 61-76; "A parte la importancia de su poesía por lo que en clla hay de delicado, de intenso, y siempre, de humano, creo que su personalidad litcraria es también importante por el crecimicnto, y casi la aparición, de procedimientos técnicos qie él aprende en ltalia y que se van a desarrollar en España a lo largo del siglo XVI, y algunos de ellos, repetidos y exacerbados por (ióngora y por sus imiladores, scrán característicos de nucstra pocsía barroca." (p. 61): Y A. Pricto, La poesía española del siglo XVl, Madrid, Cáledra, 1984, v. 1; cap. V; "Realmente la poesía de Celina no es su pocsía, en cuanto proyección de una vida interior disuclta en palabra poélica, sino la amplia aceplación y transmisión de una varia poesía renacentisla que supo ofrecer, con sus innovaciones, para el curso de una lengua poética." (p. 122). Para el análisis estilístico de la poesía de Cetina ver B. López Bueno, op. cit.; en especial para los sonetos, p. 233 y ss.; así como el prólogo que la autora realiza en su Edición, Gutierre de Cetina, Sonetos y madrigales completos, Madrid, Cáledra, 1981 , edición por la que cilaremos.

\section{${ }^{7}$ Eal. cit.; H-I.}

${ }^{3}$ Nos rmitimos principalmentc al artículo Construcción textual en los sonetos de Lope de Vega. Tipología del macrexomponente sintácico, en "Revista de Filología Española", LX, 1978-1980, pp. 23-1.57, en el que el prolesor D. Antonio (iarcía Berrio establece las líneas teóricas y analíticas lundamentales pará la configuración definitiva del macrocomponente sintáctico. Ver también A. García Berrio, Estructura y función del personaje en la lírica amorosa del Siglo de Oro, en "Lexis", IV, I, 1980, pp. 71-77. 
/1/ "El pocta lírico clásico... lenía conciencia muy marcada de que las exigencias del género que cultivaba le imponían la producción de un tipo de texto sintomático-expositivo en el que él mismo desempeñara el papel de agente"

"... textos narrativos cumplen en último término la función básica lírica sintomática, en la midida en que, o bien incluyen una referencia explícila al propio caso amoroso del poeta o bien se configura la narración como soporte de una moraleja universal, de contenido amoroso, que bien podemos considerar también relativa al propio poeta, a través de una presuposición pragmática a la que conduce su estructura general, temática y sintáctica".

/2/ La alternativa consisitía en enlatizar, a través del modo de la expresión, el papel de los actantes término y confidente".

/3/ "Otros textos...cumplirían una liunción puramente representativa, en la medida en que se trata de historias de amores de personajes ajenos al mundo del pocta, narrados dircetamente sin incidencia alguna del caso del narrador ni marca explícila de apelación". "

La construcción en los sonetos de Gutierre de Cetina responde a los esquemas tópicos de su época; una marcada tendencia dual vertebrada sobre la cesura mayor del soneto organiza la argumentación. La apelación a la Dama se construye mayoritariamente sobre esquemas constructivos de carácter discursivo sin incidencia notable de elementos enfáticos. Es también acusada la tendencia a construir el soneto mediante agrupaciones intratextuales, es decir, sin la aparición de marcas expresas que fijen la cesura y, por tanto, el cambio de orientación para el movimiento argumentativo del soneto. De igual manera, y acorde con el sentido arquitectónico que exhibe Cetina en su práctica poética, se observa la construccion a partir de esquemas en paralelo sobre solidaridades textuales formales, a diferencia de los anteriores en que la preferencia organizativa es temática. "

El análisis actancial no revela en principio una afinidad marcada por un tipo de construcción argumentativa. Esto se debe a una acusada preferencia por patrones discursivos frente a los de naturaleza enfática más cercanos a la apelación pero no exclusivos de la mísma. La apelación a la Dama cae pocas veces en un énfasis especial, se mantiene en un tono mesurado y galante facilitado, sin duda, por una artificiosidad constructiva evidente que sustenta el movimiento ingenioso propio de la terminal temática de Galanteo.

Como patrón actancial relevante para la apelación a la Dama es de señalar la tendencia a fijar desde el primer verso o primer cuarteto la filiación apelativa del soneto, como ocurre en los sonetos dirigidos a un confidente. La aparición del vocativo expreso suele marcar también la cesura mayor del soneto, según lo requiera la argumentación elegida.

Uno de los motivos que alejan las posturas de Herrera y de Cetina es la actitud de ambos hacia la amada. Tal y como ha afirmado el profesor A. Prieto "Cetina aprende una lengua de amor de las Rime diverse ajena al Canzoniere por su propia naturaleza pero también a causa del proyecto vital y poético implícito a la visión de Petrarca.

La amada de Petrarca se alza como una constelación de múltiple significado que no

${ }^{9}$ A. (iarcía Berrio, art. cit., pp. 36-37.

${ }^{10}$ Ver Anexo.

${ }^{11}$ A. Pricto, cap. cit.; "Cetina aprende una lengua de amor, pero no el amor petrarquesco. Y en este sentido el modelo de "piacevolerza" que pucde asumir de las Rime me parece muy indicativo para el recorrido de la pocsía del scvillano. Porque, naturalmente, en las Rime diverse no existe ni un punto de asmo de cancionero petrarquista." (p. 114). 
sólo se apoya sobre el juego ingenioso que la nombra y oculta, sino que también participa, en un sentido más amplio, de una esencia de sólido universo. Quizá fuera esto mismo lo que captó Herrera en su lectura del Canzoniere, desde luego en armonía con la ambición de transfigurar la práctica poética en una labor más elevada. De ahí que dote a su amada de una lejana significación que no se ciñe, unicamente, a la constelación de nombres con que la regala, sino a un principio de construcción metafórica a la manera de Petrarca.

El tratamiento poético que Cetina dispensa a la amada es bien distinto. Como acertadamente apunta la profesora B. López Bueno en su monografía sobre el poeta ${ }^{12}$ es posible hallar entre el repertorio de motivos utilizados por Cetina aquellos de ascendencia neoplatónica sobre los que se fija habitualmente la belleza de la Dama. Sin embargo, desde nuestra perspectiva, el rendimiento funcional de los mismos es escaso ya que no se erigen en denominación sustantiva del soneto sino que se pierden entre los recovecos argumentativos de una declarada actitud galante, observable para la mayora de los textos analizados. El soneto 200 Cuando a escribir de vos el alma mía, que comenta la profesora López Bueno ${ }^{13}$ como emblema de la semblanza neoplatónica que Cetina desea para su dama es tan sólo una excepción, entre otras, que no ilustra la actitud general del poeta. En los límites corteses dispuestos por el galanteo la apelación a la Dama se convierte sencillamente en eso, en la otra polaridad sobre la que desplegar un discurso galante, construido a manera de canto o de queja pero sin centrarse en el término mismo de la apelación.

A efectos argumentativos esto se observa en la falta de sonetos construidos a partir de una apelación mantenida en los cuartetos, exceptuando el soneto 45 Luz que a mis ojos das luz más serena, en el que el poeta destina a las dos primeras estrofas la descripción exaltada de las gracias de la Dama sobre una amplificación metafórica. Por otra parte en contadas ocasiones se observa un incremento semántico en contacto con el vocativo. El sistema de denominación para referirse a la amada, así como al confidente en general, es de una sencillez evidente cercana al utilizado y al modo de utilizarlo de otros poetas de su generación. Con frecuencia adopta el tratamiento neutro de Señora y rara vez se trasciende a la amada del trato protagonista que cobra la relación galante.

Herrera en sus Anotaciones marca el significado preciso del tratamiento: "Particularmente declaran los poetas que escriben cosas de amor a la que sirven por este nombre, Señora, como tirana y poseedora de su libertad" ${ }^{14}$, y lo aplica en términos exactos para su poesía, ya que sólo aparece en aquellos casos transfigurados por la ficción pastoril, relatando hechos imaginados o no, o en aquellos sonetos que se identifican plenamente con actitudes galantes en los que queda siempre implícita la relación cortés que sustenta a la apelación.

Sobre esta balanza de pesos tenues no es extraño que Herrera recriminara la falta de fuerza y el exceso de blandura, no es extraño que asemejara la poesía de Cetina con la obra de "pintores y maestros de labrar piedra y metal: que afectando la blandura y policía de un cuerpo hermoso de un mancebo se contentan con la dulzura y terneza, no

${ }^{12}$ B. López. Bucno, op. cit.; pp. $158-163$.

${ }^{13}$ Op. cit:; "La línea que conduce a lo divino, por la contemplación de la bellexa es de indudable ascendencia neoplatónica. A parece perfectamente reflejada en El Cortesano en la plálica final de Pietro Bembo. Cetina en un bello soncto expresa que la contemplación de la belleza de la dama conduce a un concepto más espiritualizado del amor" (p. 158).

${ }^{14}$ Ed. cil.; H-70. 
mostrando alguna señal de niervos y músculos..." Is. Para Herrera Canto y Queja adquieren reconcentrada intensidad por cuanto, criterios biográficos aparte, la amada de Herrera se integra en el universo metafórico de la misma creación poética.

Tampoco es extraño, por otra parte, que sea imposible identificar las distintas amadas de Cetina sino por los vagos indicios a los que una determinada senhal apunta ${ }^{16}$, ni el que se produzca una ruptura del ideal petrarquesco sobre la amada única ${ }^{17}$ al declararse Cetina en la situación antitópica, desde el canon petrarquesco, de un cambio de objeto para su pasión aunque permanezca constante la misma calidad de sufrimiento. Cetina no construye un mundo alrededor de la amada que la nombre a ella misma y por extensión, o intensión, a la propia práctica poética, sino que la deja rendida al polo cambiante de una relación cortés.

Un rasgo interesante a analizar en la poesía de Cetina con respecto a la construcción apelativa es lo que llamaremos desplazamiento de la apelación. Con esto queremos significar el cambio de focalización actancial que se produce en el texto como factor directriz argumentativo en la identificación actancial, o bien el cambio "temático" entre diversos objetos confidentes.

En la constitución del macrocomponente actancial el profesor García Berrio establece una diferencia teórica básica para explicar, a nuestro juicio, este tipo de desviación. Hemos de tener presente el hecho de que la apelación es el término marcado de la relación frente a las otras dos funciones, síntoma y representación. Su ocurrencia viene primada por una serie de marcas enfáticas, ya incidentes sobre el propio vocativo, ya puramente argumentativas, que se configuran como verdaderos patrones constructivos. La filiación apelativa de tales textos no excluye, por esta misma razón, la concurrencia de otras funciones ${ }^{18}$.

Este hecho se observa claramente en aquellos sonetos en que el confidente es mero soporte apelativo para la función sintomática predominante; a diferencia de aquellos otros en que se atribuye al confidente una carga semántica accesoria al hacerle destinatario de una advertencia, de una petición o un consuelo, por ejemplo. La naturáleza fuertemente apelativa de estos sonetos en el otro extremo de la configuración actancial provoca, en último término, el que sea posible trasplantar una oposición constructiva a otra de naturaleza temática, de manera que se distingue teóricamente en el seno del circunstante la implicación o no del confidente.

La diferencia entre las otras dos funciones, síntoma y representación, sobre el caso fronterizo de textos sintomáticos narrativos, aparece también claramente planteada para la configuración última del macrocomponente:

${ }^{15}$ Eal. cil.; H-l.

${ }^{16}$ A. Prieto, cap. cit.; "Lo cvidente es que no existen rasgos lingüísticos diferenciativos para definir a una u otra (salvo el senhal, claro está) y que ninguna de cllas provocó en cl pocta un lemguaje que la expresara y que fucse progresando secuencialmuntc..." (p. 121).

${ }^{17}$ A. Priclo, Con un soneto de Gutierre de Cetina, en "El Crotalón. Anuario de Filología Española", 1984, I, pp. 28.3-295. A propósito del soncto Un blanco, pequeñuelo y bel cordero.

${ }^{18}$ A. (jarcía Berrio, art. cit.; "La función apelativa en los textos no marca un hecho de exclusión de las otras funciones y de sus modos de expresión privativos: sino a través de la catalogación como lextos apelativos pretendemos establecer el primado constructivo de las fórmulas de énlasis apelativo en la estructura de la argumentación lextual de tales lextos" (p. 49). 
"En ocasiones hemos distinguido entre narración objeciva, como sinónimo explícito de la modalidad de expresión harrativa en función representativa, es decir, con sujeto en tercera persona distinto del pocta como sujeto de la enunciación, y simple narración o narración subjetiva, con lo que se designa cl lipo de narración en fiución sintomática, lípicamente lírica, en la qui el sujeto de la enunciación es al mismo tiempo sujelo del cnunciado" 19

Pero junto a los moldes narrativos elegidos para la exposición sintomática, tales como alegorías sobre la propia experiencia amorosa o bien el desenvolvimiento de las distintas etapas de la misma, o la meditación trascendida a partir de ella, la exposición narrativa se acerca de manera más clara a la función representativa en otro tipo de sonetos. Nos referimos a aquellos instalados en el mundo bucólico sobre el que el poeta desdobla a partir de nombres y sucesos su propia experiencia.

En estos casos el sujeto se asume en tercera persona, susceptible de una formalización representativa que con elevada frecuencia en nuestro autor se acoge a formas dialogadas en las que la dramatizacin tópica es evidente. Este tipo de textos se caracteriza por la aparición de verba dicendi que arbitran la aparición del discurso directo en el seno de la argumentación. En aquellos sonetos de construcción dual se reserva a cuartetos o tercetos la exposición del caso, estado anímico o la naturaleza del confidente apelado, lo que introduce o concluye la declaración contenida en el discurso directo. En los textos de construcción múltiple dramatizada se produce la alternancia estrofa a estrofa o bien operando sobre todo el texto.

El componente representativo en estos sonetos es evidente por cuanto el poeta establece una distancia que le permite narrar en clave de peripecia sucesos que en principio no hallarían cauce a través de la mera expresión sintomática. Es el mundo trascendido de la experiencia interior el que opera aquí, de ahí su cercanía, a instancias formales, con la función representativa.

Cetina muestra una acusada tendencia a la configuración dramatizada frente a la narrativa cuando el modo de argumentación es narrativo y no expositivo ${ }^{20}$. Sólo dos sonetos, s. 9 y s. 30, se construyen sobre esquema dual narrativo sin indicio de dramatización. En cuanto a la posibilidad múltiple no hemos registrado ningún ejemplo. La explicación en principio reside en la preferencia por esquemas duales y no múltiples tanto en la organización expositiva como en la narrativa.

Sin embargo en los abundantes casos dramatizados se observa un acusado predominio de esquemas múltiples frente a duales. La configuración actancial en principio es la misma; todas las posibilidades apelativas y representativas aparecen documentadas mientras que la función sintomática plena no determina básicamente ningún soneto dada la naturaleza apelativa-dramatizada de este tipo de argumentación que por su carácter dramatizado permite además desarrollos representativos.

La excepcionalidad de la construcción múltiple en este género de textos es evidente frente a los modos argumentativos usuales en la poesía de Cetina. Ilustra, en último término, un hábito constructivo tendente a una organización dramática del soneto más intensa que la provista por la argumentación dual, al permitir diálogos entrecruzados por diversas situaciones de una agilidad dramática superior. De igual manera el discurso directo o bien la preparación narrativa que lo antecede o concluye cobran peculiar

${ }^{19}$ A. García Bcrrio, ant cit.; p. 49.

${ }^{20}$ Ver anexo. 
efectismo al operar sobre la totalidad del texto.

No resulta sorprendente que Cetina elija para este tipo de disposición los desarrollos dramáticos más efectistas y originales, sobre todo para aquellos sonetos en función representativa que implican un alejamiento mayor que el operado sobre la función sintomática dislocada narrativamente. Es preciso decir también que la mayoría de los sonetos adscritos a este tipo de construcción no responden a las líneas tópicas establecidas para textos en función representativa, ya que en comparación con los sonetos habituales, dirigidos en nuestro autor al relato de los amores de Hero y Leandro exclusivamente, la gran mayoría se refieren a personajes inmersos en su historia amorosa o no, pero que por la disposición dramatizada de la que venimos hablando cobran una extraña autonomía cercana a la representación.

Así en los sonetos 4 Para ver si sus ojos eran cuales y 5 Como al pastor en la ardiente hora estiva, recrea la imagen de Dórida contemplando sus ojos en una fuente o escribiendo un juramento amoroso imposible en la corteza de un árbol; Así decía Dorida en el río / mirando su heldad, y el viento leve / llevó la voz que apenas fue entendida (s. 5; vv. 12-14). En el soneto 14 Sin poderse alegrar de cosa alguna, el diálogo entre Endimión y la Luna se proyecta sobre Amarilida.

Más original resulta el planteamiento dramático del soneto $207 \mathrm{~A}$ restaurar tornaba el nuevo dia afín temáticamente al soneto 206 Deje el estilo ya la usada vena no sólo porque van dirigidos al mismo confidente sino porque además descansan sobre el mismo artificio literario, la imagen de un espíritu habla con su hijo, trasplantando un motivo temático de índole amorosa; la imagen de la amada que difunta acude a hablar con el poeta. Sin embargo la organizacin argumentativa de los dos sonetos es distinta pues en el s. 207 Cetina proyecta su voz sobre el "padre" que consuela al hijo de la pérdida a través de una argumentación dramatizada en la que el discurso directo recubre la casi totalidad del texto a partir de la introducción en el primer cuarteto de la situación dramática que lo genera : A restaurar tornaba el nuevo día / la aurora, cuando el sueño le mostraba / al pastor principal que nos guardaba, / la imagen que, ya muerta, en él vivía (s. 207 vv. 1-4).

Posibilidades que hemos traido como ejemplo integrable sobre el corpus de otras muchas de Cetina en las que se observa la afinidad a esquemas dramáticos que confieren al soneto una movilidad efectista. Si bien es posible hallar en otros autores composiciones semejantes a estas pues responden a patrones literarios comunes, el procedimiento argumentativo subyacente cobra en la práctica poética de Cetina relevancia especial por la intensidad y frecuencia con que se aplica de manera que se erige en un dispositivo creador propio.

La misma tendencia a construir los textos sobre estructuras dramatizadas se observa en aquellos sonetos en los que el poeta apela a sí mismo. La identificación primaria es sintomática frente a los textos representativos. Esta diferencia parece evidente en aquellos sonetos en los que se produce un desplazamiento de la apelación a partir de estructuras narrativas dramatizadas y que tópicamente se adscriben a la modalidad de apelación al poeta mismo, caso límite entre formalización apelativa y función sintomática.

La apelación al poeta mismo guarda en Cetina los márgenes dispuestos por la tradición. Es apreciable una tendencia marcada a los efectos artificiosos que procura la construcción antidistributiva, ya como primado argumentativo (ss. 166 y 194). o bien sobre la base de una estructura dramatizada (s. 20) o plenamente dramática y de factura dialogada (ss. 81; 82; 83 y 134). En los demás casos el poeta construye la apelación según los patrones habituales registrados en la apelación a la Dama o al Confidente (ss. 25; 34; $39 ; 139 ; 184 ; 186$ y 193 ).

La tendencia a la disposición "dramatizada" de los textos, marcada por la frecuencia 
de casos, es la que explica el desplazamiento apelativo en el soneto 185 i Ay sabrosa ilusión, sueño süave. El poeta comienza con una invocación al sueño que le engaña prometiéndole falsas visiones. Es en el primer terceto en el que el poeta "narrativiza" la situación al introducir la situación dramática que genera el texto para reintroducir en el segundo terceto, a la manera narrativa, cercana a los moldes tópicos establecidos para la ficción pastoril, la apelación al sueño ${ }^{21}$ :

"Bien conozco que ducrmo y que me engaño, mientra envuclto en un bien falso, dudoso, manifiesto mi mal se muestra cierto.

Pero, pues excusar no puedo un daño

hazme sentir, oh sueño pïadoso!, antes durmiendo el bien, que el mal despierto."

(vv. 9-14)

Lo mismo ocurre en el soneto 146 Del más subido ardor, del más precioso. Un esquema narrativo de corte sintomático aparece en los cuartetos, sin embargo en los tercetos el poeta se dirige a un espectador ficticio para luego dirigir la voz cambiante al amor:

"A quien sè dio jamás, pues, tal tormento?

Dónde se vió, decid, que un mal tan alto

venga envuclto en un bien que par no liene?

Amor, gracias te doy por lo que siento:

razón sobra al dolor, y della fallo,

teme el honroso mal que de ti viene"

(w. 9-14)

El desplazamiento apelativo es un fenómeno habitual en este tipo de apelación más cercana por su naturaleza temática al síntoma que a la apelación a la Dama o al Confidente, aunque, como ya hemos señalado para Cetina, observación generalizable a otros autores, la apelación al poeta mismo adopta con frecuencia las tendencias constructivas operantes en los otros dos tipos de apelación ${ }^{2}$.

${ }^{21}$ La misma disposición, por otro lado tópica, aunque no privativa, para los sonctos dirigidos al sueño, "ministro de engaños", se observa, por cjemplo en el soneto XLI Dulce soñar y dulce congoxarme de Boscán: $O$ sueño! quánto más leve y sabroso / Me fueras, si vinieras tan pesado, / Que asentáras en mí con más reposo // Durmiendo, en fin, fui bienaventurado; / Y es justo en la mentira ser dichoso / quien siempre en la verdad fué desdichado. (vv. 9-14). Cilamos por la edición de W. I. Knapp, J. Boscán, Las obras de Juan Boscán (Repartidas en tres libros), Madrid, 1875.

22 Un caso límitc lo constituye, por ejemplo, la apelación al Amor combinada con apclación a la Dama en dos sonetos de Hurtado de Mendoza; s. 27 Amor me dijo en mi primera edad; y s. 36 Ciracia te pido Amor. No la merece. Citamos por la edición que prologa P. Bohigas, D. Hurlado de Mendoza, Epístolas y otras poesías, Barcelona, Montaner y Simón, 1944. La apelación a la Dama se sitúa en la obra de este atutor, por lo general, en el último terceto a diferencia de Celina que prefiere identificar actancialmente el texto desde un principio o utilizar la apelación en las cesuras estróficas como verdadero eje organizador del discurso. La entrada, sorpresiva a veces, de la apelación a la Dama al final de un soneto, revela una construcción que da pic a los más variados desarrollos argumentativos a lo largo del texto sin que interfieran necesariamente con un planteamiento 
Sin embargo no resulta en principio tan habitual, aunque sí explicable, el desplazamiento que opera en otros textos. Tomemos como ejemplo el soneto 224 Cual en la deseada primavera; Se mantiene en los cuartetos la exaltada apelación vocativa mediante símiles a la Marquesa del Vasto, destinataria del soneto sobre los dispositivos habituales del discurso amoroso. El tránsito abrupto a los tercetos se realiza a través de una marca enfática, un imperativo, y un cambio, igualmente abrupto, de la focalización actancial que pasa del término a un confidente, el pueblo que espera su llegada y entre el que el poeta se situa.

La descripción de los valores que atesora la Marquesa en estrecha relación con su llegada mediante una amplificación metafórica reproduce para la conciencia tópica del poeta la situación "narrativa" sobre la que se construye el texto. En este caso el abrupto cambio operado en los tercetos no aparece introducido por los verba dicendi habituales para este tipo de movimiento dramático aunque sí la exposición del caso que lo introduce, la espera del pueblo. El poeta se distancia dramáticamente de la acción como mentor de la misma a través del soporte que procura la aparición de un circunstante espacial.

De la íntima conexión que guarda para Cetina el desplazamiento apelativo con marcas espaciales narrativas da cuenta el soneto 37 Padre Oceano, que del bel Tirreno. El efectismo dramático, en este caso, es más complejo. La apelación al Oceano se tematiza en los cuartetos estableciendo desde ellos el punto de unión, Tirreno hijo de Oceano, para tematizar en los tercetos una apelación al río sobre el "escenario", circunstante espacial, de una peripecia. En los tercetos la disposición narrativa dramatizada es inequívoca y el soneto exhibe una construcción dual en la que es evidente el desplazamiento de la apelación al confidente a la narración de la peripecia a sụ vez construida sobre una apelacin al río que subyace a la acción dramática. No se trata de un soneto "confuso" como lo califica M. J. Bayo ${ }^{2}$, sino de una construcción artificiosa en virtud de la organización dramática que Cetina desea para el soneto:

Padre Occano, quc del bel Tirreno

gozas los amorosos abrazados

de gloria, si sintieses mis cuidados,

cuanto yo de pesar, estarías lleno.

En la parte del ciclo más sereno, para colmar la cima de lus hados, ví a tu hijo bañar los delicados

pies de una ninfa que nació en su seno.

"Ay, quién fuese hora tú", yo le decía, y de puro celoso lo enturbiaba

con llanto que del alma me salía.

Mas él, que tanto bien comunicaba, micntra con mi llorar lo revolvía, claro en sus ondas mi dolor mostraba.

apelativo primario. Quizá sea ésta una de las razones que explique el desplazamiento de la apelación en estos sonetos, así como el que se apoyen sobre una apelación al poeta mismo, transfigurado en el amor, y a través de un esquema narrativo, cercano a los moldes tópicos que hemos señalado para las estructuras dialogadas dramatizadas.

${ }^{3}$ M. J. Bayo, Virgilio y la pastoral española del Renacimiento (1480-1550), Madrid, Gircdos, 1970; p. 168. Para (juticrre de Cetina, pp. 16.3-172. 
De la misma manera, en el soneto 33 Dulce, sabrosa, cristalina fuente, la apelación se desplaza de la fuente al Amor. En este caso no se trata de un cambio de la modalidad actancial sino de una variación del objeto confidente, ya que el cambio abrupto no viene determinado por la misma "peripecia" que en el caso anterior es tema principal sobre una estructura narrativa. Para este soneto la "peripecia" opera como tema secundario o mero pretexto a partir del que reflexionar sobre los contrarios efectos del agua sobre el pecho de la amada. La deixis, como formalización explícita de la dramatización, es marca del circunstante de escenario mediante el que el poeta ensaya y asegura a la vez el desplazamiento apelativo hacia el Amor, esta vez no transfiguración de sus sentimientos sino divinidad ajena, y mediante el que posibilita, además, una dramatización extraña a los moldes narrativos dramatizados. La variante que anota B. López Bueno en su Edición no es más que un desarrollo tópico de la apelación a la fuente.

De las supuestas habilidades del dramaturgo que fue Cetina, según semblanza de Pacheco, no nos ha quedado ningún testimonio aunque sí del "Diálogo entre la cabeza y la gorra". Por otra parte, como apunta J. M. Blecua, se observa en los tres romances debidos a Cetina "influencias del romance viejo, ya que en ellos predomina el monólogo o diálogo...", habida cuenta de que "en términos generales, la técnica del romance viejo es una técnica dramática" ${ }^{24}$. Actitud similar es la que muestra Cetina al componer sus sonetos; una tendencia constructiva hacia la configuración dramatizada que provoca en determinados casos el desplazamiento de la apelación y que contamina a otras construcciones, en principio expositivas, los mecanismos tópicos arbitrados para el tipo de argumentación narrativa.

La lejanía de la amada, que antes apuntábamos al considerar los textos en apelación a la Dama, es a la vez acercamiento doloroso y obsesivo al propio dolor ${ }^{25}$. La expresión lírica, la función sintomática, se pierde en tortuosos análisis cuya atracción de abismo por la poesía de A. March no es tan sólo afición de gusto sino el patrón más cercano reconocido para la propia expresión ${ }^{20}$. Cetina se erige en sujeto de conocimiento más que de sentimiento amoroso a través de este desdoblamiento que reserva para la dama la relación cortés, principalmente, con entradas sintomáticas que, con frecuencia, se doblegan, en virtud del galanteo como tema básico, al juego cambiante de amores y desamores y a la voluntad, también, de quebrar por el halago la férrea voluntad.

La introspección psicológica aprendida del Canzoniere, filtrada por entre las viejas composiciones de nuestro Cancionero a la vez que disgregada de su núcleo e intención inicial en las Rime diverse, y el sesgo lúcidamente desesperado que cobra en la poesía de March es la lengua de conocimiento amoroso que aprehende Cetina para la expresión de

24. M. Blecua, Poemas menores de Gutierre de Cetina, en Sobre poesía de la Edad de Oro, Gredos, Madrid, 1970; pp. 185-199; p. 45.

8s Ver anexo.

${ }^{26}$ B. López Bueno señala acertadamente en el prólogo a Ed. cit. que "el rígido ideario establecido de base aristotélico-tomista" que fluye de la poesía de Ausias March configura un "mundo tan propio |que| difícilmente pucde ser asumido por otro poeta", de aquí las diferencias tanto a nivel formal como de contenido ya que "la radical seriedad del "pocta-filósofo" se frivoliza de alguna manera al no continuarsc hasia el final las silogísticas argumentaciones" (p. 42). Sin embargo, y desde nuestro punto de vista, lo que acerca a ambos autores es la observación distanciada del sentimiento amoroso, y no, como apunta B. López. Bucno, las diferencias lógicas entre dos épocas radicalmente distintas. 
su propio sentimiento.

Si bien son abundantes en la poesía de la época las conclusiones dirigidas a un público ficticio, el deseo de ejemplarizar mediante el propio caso, las sentencias y conclusiones lapidarias, es en la poesía de Cetina donde esta actitud de conocimiento trascendido cobra especial relevancia.

La aparición de la Dama en los textos sintomáticos es escasa. En los sonetos 64 Mientras con gran terror por cada parte y en el s. 187 Cuando a contemplar vengo el curso breve, se debe a la organización de los modelos elegidos para imitar, si bien en el s. 64 , imitación del soneto de Giovanni Mozarello Mentre $i$ superbi tetti a parte a parte, de varia fortuna, ajusta Cetina artificiosamente la relación metafórica entre Nerón y su Dama de manera explícita, según práctica habitual de nuestro poeta.

En los otros dos sonetos en que se hace referencia a la amada, s. 49 Mientra, por alegrame, el sol mostraba y el s. 196 Con la casta virtud vide abrazado, ésta aparece como personaje de una ficción narrativa así como en el s. 28 Mientra el fiero león, fogoso, ardiente, donde la presencia poética de la dama se ciñe al hecho concreto de una ausencia sobre el pie cambiante de la querida tensión de contrarios. En el s. 30, De las doce a las cuatro había pasado, sobre la metáfora de la dama-sol y transfigurada la voz del poeta en la de Vandalio el soneto discurre por un cauce narrativo, también.

En los demás sonetos de corte sintomático la relación concreta con la amada no aparece. Es por esta razón por la que la poesía de Cetina y en concreto la expresión de su sentimiento resulta extrañamente autónoma y a la vez reiterativa. Se trata de investigar sobre el propio dolor, hasta la nausea, mediante personificaciones que las más de las veces no resuelven la herencia medieval para una poesía que se desea nueva.

No creemos que se trate en principio de una supuesta evolución hacia fórmulas más abstractas y cerebrales ${ }^{2}$. Las dos formas conviven en otros autores puesto que se trata de una manera de configurar la expresión del dolor o del gozo y enfrentarlo a la fuente de la que brotan; pero la marcada fascinación hacia la poesía de A. March en contrapartida con la tierna "piacevolezza" que no recae sustantiva en la amada contribuyen a producir esta suerte de desdoblamiento en la poesía de Cetina.

Por otra parte ya observó el profesor D. Rafael Lapesa que entre las múltiples diferencias que se puede constatar entre la poesía de Garcilaso y la de Cetina una de las más evidentes es que "Garcilaso concentra, filtra, su fondo anímico, que pasa al verso refrenado; acrisolado por la depuración: Cetina es pródigo y difuso; amontona quejas, se desborda sin concentrarse... Desprovisto de serenidad para seleccionar, Cetina cae en la extremosidad lamentatoria" ${ }^{28}$.

Garcilaso se apropia de un sentimiento proyectado en ajustada armonía con la actitud que muestra hacia la amada. Ambos son términos equilibrados de un "dolorido sentir". El lastre medieval se abandona progresivamente en una "trayectoria poética" que delimita clara la voz personal. A diferencia de la poesía de Cetina y de la de los otros autores pertenecientes a su generación, Garcilaso asimila el material que se presenta tópicamente como referente obligado para la configuración proyectada del propio sentimiento, y lo instala en el cercado reino de su experiencia interior.

${ }^{27}$ B. López Bueno, un el Prólogo a su ed. cit.; "Crecmos así ver una cvolución en la obra del poeta sevillano, desde el mundo sensible y cromálico del bucolismo que presidía su idilio con Dórida, enmarcado en el arcádico Betis, hacia un progresivo intelectualismo cada vez más adepto a formulaciones abstractas" (p. 45).

28 R. Lapesa, art. cit.; p. 252. 
Así en el soneto XII Si para refrenar este deseo ${ }^{*}$, Garcilaso introduce un artificio literario; es la visión de la pintura de los terribles males acaecidos a Icaro y Faetón lo que le lleva a reflexionar sobre su propio estado no la meditación, en el fondo ajena, acerca de la "cualidad" emblemática de sus casos como referente que amplifique o pondere el propio sentimiento. De la misma manera al relatar la transformación de Dafne en el soneto XIII $A$ Dafne ya los brazos le crecían, el poeta se sitúa ante la metamorfosis directamente, es él el que lo ve; enverdes hojas ví que se tornaban / los cabellos qu'el oro escurecían (vv. 3-4).

La integración del material tópico arbitrado por la tradición se ubica en la voz poética y la experiencia personal, es la experiencia interior predominante y organizadora de manera que el símil elegido no cobra la distanciada independencia observable en otros autores que, como Cetina, asumen los inicios de una práctica poética nueva, sin asimilarla del todo, de manera que se vuelva, como en Garcilaso, pleno y dúctil instrumento al servicio de la propia expresión.

Nótese a este respecto, y de forma meramente ilustrativa de lo que venimos diciendo, el tratamiento que, por ejemplo, Garcilaso y Cetina deparan a los efectos que provoca la tópica "herida de amor". Garcilaso en el soneto XVIII Si a vuestra voluntad yo soy de cera se recrea ante el poder de la amada para exclamar en el segundo terceto; Mas si de cerca soy acometido / de vuestros ojos, luego siento helado / cuajárseme la sangre por las venas (vv. 12-14). Sobre el mismo motivo Cetina se prodiga en una teorización que deja ensombrecida la relación con la Dama y a la vez distancia la expresión del dolor. Así, por ejemplo, en el soneto 128 :

\footnotetext{
Cuando del grave golpe es ofendido el cuerpo, de improviso es lastimado, o por nuevo accidente es alterado por caso de que no fue prevenido,
}

La sangre corre luego al desvalido corazón como a micmbro señalado, y de allí vá a para a do el golpe ha dado, de do nace el quedar descolorido.

Hizo en mi pecho Amor mortal herida; corrió luego la sangre allí altcrada y reparóse donde estaba el daño.

De allí quedé con la color perdida: al rostro el corazón se la ha usurpado para favoresecr su mal exiraño.

Como ha señalado el profesor A. Prieto en relación con el soneto Un rato se levanta mi esperanza el viraje marcado por los tercetos; yo mesmo emprender a fuerza de brazos (v. 9) "está señalando claramente la acción, ese ir tras la meditación, que le distingue, personalizándolo del estímulo ajeno" ${ }^{30}$. En la poesía de Cetina no se produce ese paso

20 Citamos por la edición de E. L. Rivers, Garcilaso de la Vega, Obras completas, Madrid, Castalia, 1981.

30 A. Pricto, "Con un soncto de Gutierre de Cetina"...; p. 291. Ver también A. Pricto, El "Cancionero" petrarquista de Garcilaso, en "Dicenda. Cuadernos de Filología Hispánica", 1984, 3, pp. 97-115. A partir del análisis del soncto garcilasiano, De aquella vista pura y excelente, señala el contenido doctrinal primario que 
ulterior porque la función sintomática recae única sobre sí misma, construyéndose a la manera de una sala de espejos de forma que se produce un efecto de aislamiento y a la vez de distancia. La alegoría tradicional proyectada sobre las potencias, el símil artificioso ${ }^{31}$ tomado en especial de la poesía de March, el "Como ... así", o la referencia a "supuestos" de la teoría neoplatónica que dan juego a las más artificiosas variaciones, delatan, en el fondo, tanto la falta de asimilación de un lenguaje poético que dispone de sus universos de referencia, como la constante voluntad de un poeta que observa y analiza la realidad en trasplante riguroso a su propio sufrimiento, a la vez que somete sus meditaciones, en constante lucha, a lo que ha de ser y lo que sin embargo es.

Por otra parte al igual que señalábamos una tendencia a la construcción dramatizada del soneto y la adopción de moldes representativos que implican, por su naturalezá, una voluntad de distanciamiento, lo mismo puede decirse de la configuración que adquieren los textos en función sintomática. En un elevado número de casos el poeta se situa en una atalaya desde la que "narrar" fuera del tiempo las distintas situaciones a las que da pie la expresión sintomática.

Se trata de una actitud ilustrada en la teoría por el profesor A. García Berrio entre "el tiempo objetivo (narrativo), centrado en el enunciado, frente al tiempo de expresión (expositivo), centrado en la enunciación" ${ }^{32}$. La frecuencia con que Cetina acude a esquemas narrativos a la vez que la disposición de los mismos frente a la exposición sintomática pura en el texto, provoca un acusado desdoblamiento entre el "tiempo objetivo", desde el que se "narra" una situación de principio a final, y el "tiempo de la expresión" destinado a la pura exposición sintomática.

Esta oposición, presente en otros poetas aunque no de manera tan acusada como en Cetina, explica, por ejemplo, la "atopicidad", desde el supuesto petrarquista, que para el soneto Un blanco, pequeñuelo y bel cordero señala el profesor A. Prieto ${ }^{33}$. El poeta se

adcmás de significar una innovación temática para la evolución de la pocsía petrarquista española, es también un estadio anterior en el descnvolvimiento de un cancionero a la manera de Pétrarca; "cuando aún su saber (el saber del clocuente) priva especialmente sobre la experiencia del sentimicnto" (p. 113). El "saber del clocuente" es el estadio en el que queda la poesía de Cetina, el saber del conocimento que no haya cauce trascendido. La evolución que sugiere la poesía de Garcilaso fuera de los márgenes concretos de un Cancionero querido o no, es en realidad la mayor innovación del pocta con respecto a la poesía praclicada por sus coctáneos y que marcará, a su vez, la evolución definitiva para las siguientes generaciones.

${ }^{31}$ Sobre el efecto que provoca la comparación en la pocsía de A. March remitimos al lector al estudio de R. Archer, The persuasive image. The Role of Analogy in the poetry of Ausias March, Amsterdam / Philadelphia, J. Benjamins, 1985. Una de las más interesantes conclusiones a las que llega el autor en su estudio es; "The trie locus of the simile, as March uses it, is the poem as a whole, not merely the stanza in which it appears." El mismo efecto produce la aplicación frecuente de este esquema en la poesía de los autores de la primera gencración, en especial evidente en aquellos textos en los que la comparación se reserva a los tercetos, o bien al último terceto, lugar de decisión temática para el soneto. El efecto es más intenso cuando la comparación se pone al servicio de la función sintomática micntras que en textos apelativos o representativos por su propia naturaleza semántica la comparación adquiere un movimiento accesorio al desplazar el efecto dominante del símil hacia contenidos actanciales distintos.

${ }^{32}$ A. García Berrio, ant cit; p. 49.

${ }^{33}$ A. Prieto, "Con un soneto de (jutierre de Cetina", art. cit.; "El versátil Cetina (tan alejado del amor único modelado por Petrarca para sujetar un Cancioncro, tan distanciado del sentimiento dominante de (jarcilaso dando íntima conexión a su cancioncro) ha ido montando, en este soncto, una perfecta gradación narrativa, su proceso de perder a Dórida tras un presente del que ya tan sólo "resuena ahora" la advertencia de algo que se lo llevaba. Ese algo cra el propio sentimiento del poeta, con sus circunstancias, inclinándose hacia Amarilida" 
sitúa en el tiempo objetivo para relatar su alejamiento de Dórida en favor de Amarílida. No sólo se trata de una ruptura del canon establecido por Petrarca sobre la amada única, supone además la ubicación definitiva de la voz poética en el tiempo del enunciado, no de la enunciación. La distancia radical que opera en este soneto le acerca, en una segunda gradación, a esquemas no ya narrativos sino puramente representativos.

Cetina se erige en un sujeto de conocimiento amoroso, como ya hemos dicho, que contrasta con la realidad literaria o no, los avatares desdichados de su sentimiento. Es esta observación la que le hace caer en quejosas exclamaciones, en denodados intentos por ajustar a su caso lo que es general, y lo que confiere en último término a su expresión una rara apariencia entre la que se mezcla una reiterativa "extremosidad lamentatoria" a la vez que una aparente falta de fuerza. De la misma manera se sitúa con frecuencia fuera del tiempo, como observador no exento de pasión.

Este alejamiento que hemos señalado no sólo para la función sintomática sino también para la relación establecida con la amada además de la tendencia a disponer para el soneto una configuración dramática en la que la voz del poeta "representa" acciones propias como aịenas, ilustra también, a nuestro parecer, la distancia cobrada ante el propio ejercicio poético. Como ha señalado el profesor D. Rafael Lapesa:

"En Petrarca o en (Garcilaso sería inconecbible la autocrílica burlesca; surge la idea de la vanidad del afán pasado ("fra le vanc speranza e'l van dolore"), o la liberación penosamente conseguida ("Gracias al cielo doy que ya del cuello - de todo el grave yugo he sacudido"); pero no desaparece el respeto a la propia creación, que ha brotado al calor de impulsos emocionales hondamente sentidos" ${ }^{34}$.

\section{Anexo}

Incluimos el análisis actancial y argumentativo de los sonetos. Para una aclaración teórica detenida de los conceptos que utilizamos, remitimos al art. cit. en nota del prolesor D. Antonio (iarcía Berrio.

/A/: Apclación. /A1/ Apclación a la Dama; /A2/ Apclación al Confidente y /A3/ Apelación al poeta mismo,

/B/: Síntoma.

$/ C /:$ Representación.

/1/ Isodistribución dual con marcas explícitas, enfático, vocativo-imperativo.

/2/ Isodistribución dual con marcas explícitas, enfático, vocativo-exclamativo.

/3/ Isodistribución dual con marcas cxplícitas, enfático, discursivo-enfático.

/4/ Isodistribución dual con marcas explícitas, enfático, enfático-discursivo.

(p. 295).

${ }^{34}$ R. Lapesa, ant. cil.; pp. 249-250. 
/5/ Isodistribución dual con marcas explícitas, enfático-discursivo, mixto.

/6/ Isodistribución dual con marcas explicitas, no enfático, discursivo.

/7/ Isodistribución dual sin mareas explícilas, agrupaciones intratextuales.

/8/ Isodistribución dual sin marcas explícilas, paralclismo.

/9/ Isodistribución múltiple, climax.

/10/ Isodistribución múltiple, vario.

/11/ Antidistribución plurisentencial.

/12/ Antidistribución unisentencial.

/13/ Narración dual dramatizada.

/14/ Narración dual narralivo.

15/ Narración múltiple dramatizada.

/16/ Narración múlliple narrativo.

\section{/A1/ APELACION A LA DAMA}

/1/ 224

/2/ 45

$13 / 46 ; 104 ; 105 ; 247$

/4/ $23 ; 43 ; 44 ; 47 ; 52 ; 119$

$/ 5 / 50 ; 62 ; 69 ; 100 ; 102 ; 158 ; 159 ; 179 ; 219 ; 225 ; 235$

/6/ $58 ; 59 ; 90 ; 91 ; 118 ; 122 ; 127 ; 136 ; 140 ; 149 ; 152 ; 153 ; 163$;

$170 ; 217 ; 232$

$/ 7 / 29 ; 41 ; 63 ; 66 ; 87 ; 93 ; 96 ; 101 ; 103 ; 107 ; 109 ; 110 ; 114$

$164 ; 173 ; 200 ; 204 ; 205 ; 225 ; 231$;

$/ 8 / 40 ; 53 ; 60 ; 61 ; 65 ; 67 ; 68 ; 70 ; 78 ; 89 ; 97 ; 111 ; 112 ; 124$

$131 ; 141 ; 149 ; 150 ; 176 ; 197 ; 218$

$19 / 175$

$/ 10 / 78 ; 84 ; 86 ; 113$

$/ 11 / 98 ; 99$ 
$/ 12 / 55 ; 106 ; 147 ; 209$

$/ 13 / 3 ; 21 ; 95$

$/ 14 /$

$/ 15 / 8 ; 10 ; 14 ; 15 ; 17 ; 38$

$/ 16 /$

/A2/ APELACION AL CONFIDENTE

/1/

$/ 21$

$/ 3 / 36 ; 209 ; 211 ; 213 ; 221 ; 229 ; 241$

$/ 4 / 37 ; 148 ; 203 ; 244 ; 250 ; 252$

$/ 5 / 76 ; 172 ; 212 ; 216 ; 243$

$/ 6 / 210 ; 220 ; 222 ; 236$

$/ 7 / 32 ; 74 ; 181 ; 223 ; 245$

$/ 8 / 6 ; 33 ; 48 ; 51 ; 80 ; 208 ; 214 ; 215 ; 237 ; 238 ; 242 ; 251$

$/ 9 / 171$

$/ 10 /$

$/ 11 / 22 ; 71 ; 125 ; 132$

$/ 12 / 239$

$/ 13 / 16 ; 26 ; 27 ; 35 ; 234$

$/ 14 /$

$/ 15 / 1 ; 12 ; 18 ; 24 ; 31 ; 56$

$/ 16 /$

/A3/ APELACION AL POETA MISMO

$/ 1 /$

$/ 21$

/3/ 189; 193

$/ 4 / 140$

/5/ 185

/6/ 139; 190

64 
$/ 7 / 39 ; 135$

$/ 8 / 34 ; 73 ; 137 ; 168 ; 186$

$/ 9 / 184$

$/ 10 / 166$

$/ 11 /$

$/ 12 / 194$

$/ 13 / 25 ; 160$

$/ 14 /$

$/ 15 / 20 ; 81 ; 82 ; 83 ; 134$

$/ 16 /$

/B/ SINTOMA

/1/

$/ 2 /$

$13 / 206$

/4/ 133; 177; 183

/5/ 75; 182; 199

$/ 6 / 2 ; 64 ; 85 ; 92 ; 94 ; 121 ; 138 ; 142 ; 187 ; 191 ; 192 ; 201$

$/ 7 / 28 ; 49 ; 88 ; 123 ; 128 ; 143 ; 154 ; 162 ; 174 ; 178 ; 196$

$/ 8 / 72 ; 108 ; 120 ; 145 ; 151 ; 180 ; 188 ; 198 ; 202$

$19 /$

$/ 10 / 11 ; 77 ; 156 ; 161 ; 165 ; 167$

$/ 11 / 129$

$/ 12 / 13 ; 79 ; 157 ; 195$

$/ 13 /$

$/ 14 / 9 ; 30$

$/ 15 /$

$/ 16 /$

/C/ REPRESENTACION 
$/ 7 / 126$

$/ 8 / 144$

$19 /$

$/ 10 /$

$/ 11 /$

$/ 12 /$

$/ 13 / 115 ; 116 ; 228 ; 230 ; 248$

$/ 14 / 9 ; 30$

$/ 15 / 4 ; 5 ; 7 ; 117 ; 1.55 ; 207 ; 226 ; 227$

$/ 16 /$ 